\title{
The neverending story keer terug as Die eindelose storie vir jong en ouer generasies
}

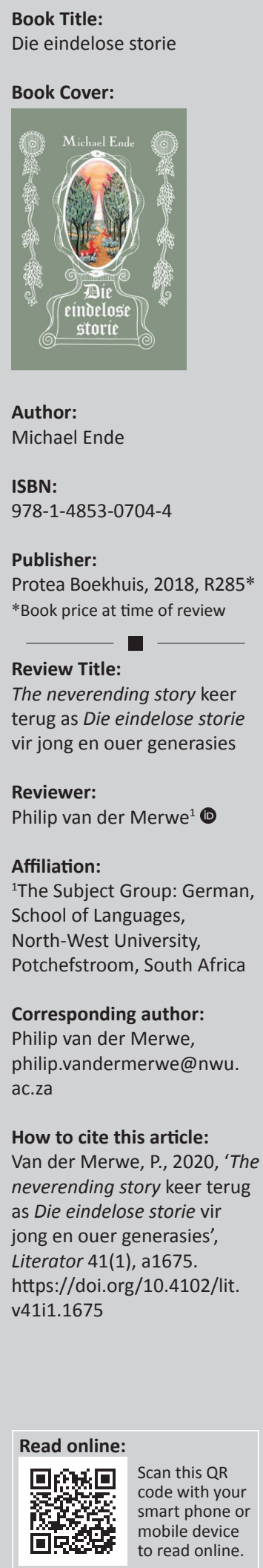

Die titel The neverending story kan dalk vir Generasies $\mathrm{Y}$ en $\mathrm{Z}$ assosiasies met die 'ou', maar steeds maklik verkrygbare 1984-film oproep. Dit kan dalk ook nostalgie wek by Generasie X wat die film tydens die tagtigerjare gesien het en die seuntjie onthou wat op die donserige geluksdraak vlieg. Hulle het stellig ook na die bekende temalied van Limahl saam met ander 1985-treffers soos Madonna se 'Like a virgin' en Modern Talking se 'You're my heart, you're my soul' op Springbokradio geluister. Dan is daar diegene wat die boek gelees het: Ralph Manheim se 1983-vertaling, die oorspronklike Duitse boek deur Michael Ende, of een van die ander talryke vertalings. Sedert Die unendliche Geschichte 40 jaar gelede (in 1979) verskyn het, het dié boek, saam met Gunther Pakendorf se (waarskynlik jongste) vertaling, die lig in sowat 40 tale gesien.

Die eindelose storie is ' $n$ aanskoulike boek. Protea Boekhuis behou die gees van een van Thienemann se verskeie uitgawes met die voorkoms van hierdie fantasieroman. Binne-in die boek volg na die titel: 'Van A tot Z met letters en illustrasies deur Roswitha Quadflieg'. Die boek het 'n groen omslag met 'n ovaalvormige 'venster' omring deur twee slange wat mekaar se sterte byt. In kontras met die groen 'muur', kyk 'n mens deur hierdie venster na 'n kleurryke toneeltjie van 'n kronkelpad met afraaipaadjies tussen 'n laning bome wat na die Ivoortoring, die tuiste van die Kinderlike Keiserin, lei. In die bome is eksotiese voëls en op die kronkelpad is eenhorings.

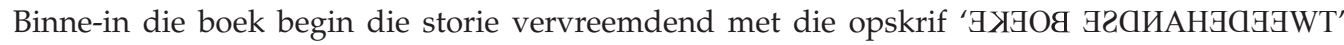
(bl. 5) soos wat Bastian, die klein vet seuntjie met krom bene wat van boelies af weggehardloop het, van die binnekant van 'n boekwinkel na die letters op die glasdeur kyk. In die boekwinkel gaps hierdie klein storieliefhebber die boek met die veelbelowende titel: 'Die eindelose storie'.

Die teks oor Bastian se (werklike) wêreld verskyn in rooi letters; wat egter in 'Fantásië' afspeel, is in groen gedruk. Maar hierdie wêrelde bly nie apart van mekaar nie. In Afrikaans word Ende se nuutskepping 'Phantásien', met die klem op die tweede 'a', nageboots. Die vertaler slaag daarin om Ende se verbeeldingsvernuf - wat die naam 'Fantásië' ook impliseer - oortuigend en indrukwekkend in Afrikaans aan te bied. Lees byvoorbeeld die beskrywing van die aanwesigheidslys tydens die vergadering met die Kinderlike Keiserin aan die begin van die storie:

Daar is dwergdokters met wit baarde en boggelrûe, daar is feë-artse in skitterende silwerblou gewade en met vonkelende sterre in hulle hare, daar is watermense met groot mae en gewebde hande en voete (spesiale baddens is vir hulle ingerig), maar daar is ook wit slange, inmekaar gekronkel op die lang tafel in die middel van die saal. Verder is daar bye-elwe, ja selfs towenaars, vampiere en geeste, wat oor die algemeen nie as besonder hulpvaardig en bevorderlik vir die gesondheid beskou word nie. (bl.33)

Die eindelose storie is die komplekse versameling ervarings van Bastian Balthazar Bux wie se eie wêreld skakel met Fantásië, wat reeds op verskeie plekke deur die Niet uitgewis is. Die Kinderlike Keiserin stuur Caïron, 'n swart sentour, na Atreju toe. Atreju is 'n Groenhuidseuntjie met blouswart hare, wie se mense 'n volk van buffeljagters is (bl. 39). Hy moet aan hom die medalje AURYN oorhandig, 'n soort wapen wat 'geheime vaardighede aan die draer verleen' (bl. 37). Atreju word daarmee aangestel om redding vir die kwynende Fantásië te vind. So begin dan die avontuurryke reis van Atreju waaroor Bastian in 'n pakkamer van sy skool lees. Die redding kan egter slegs van 'n mensekind kom wat aan die Kinderlike Keiserin 'n nuwe naam moet gee.

Atreju word van Bastian bewus, en in groen letters word vertel hoe Bastian 'n vet seun met 'n bleek gesig sien: 'omtrent so oud soos hy self, wat met gekruisde bene op 'n bed van matte 'n boek sit en lees' (bl. 99). Kort daarna volg in rooi letters: 'Bastian skrik toe hy besef wat hy pas gelees het' (bl. 100).

Copyright: @ 2020. The Authors. Licensee: AOSIS. This work is licensed under the Creative Commons Attribution License. 
Wanneer Bastian begin lees, begin elkeen van die hoofstukke van die begin tot aan die einde van die boek, van A tot $Z$, met 'n versierde beginletter op ' $n$ hele bladsy - in slegs groen en rooi. Nadat'n mens elke hoofstuk gelees het, kan jy na hierdie bladsy terugkeer en retrospektief die geilllustreerde karakters, wesens en tonele identifiseer; daaroor besin of vir ' $n$ wyle daarin ontvlug. Waarom die letters juis in alfabetiese volgorde verskyn, vind die leser ook wel mettertyd uit in hoofstuk 23: 'Die ou keiserstad' (bl. 363-382).

In hierdie avontuurroman beland Bastian uiteindelik self in Fantásië. Dit herinner aan Wendy Darling wat haar weg na Neverland vind, of Alice na Wonderland. Maar verlei deur sy status as die 'Redder van Fantásië' sowel as sy nuwe skeppingsmag om Fantásië uit te brei, word Bastian, die eens deerniswekkende seuntjie, 'n hoogs onaangename, selfgesentreerde spierpaleis wat homself as 'n superheld sien. Die prys van sy skeppingsdade is dat hy sy herinneringe aan sy vorige lewe een vir een verloor, totdat daarvan bykans niks oorbly nie. Op 'n manier moet hy na sy eie wêreld terugkeer om rampspoedige gevolge te voorkom, maar dit kan hy slegs doen deur sy 'ware wens' - dit verskyn ook as 'n opdrag op AURYN: 'DOEN WAT JY WIL' (bl. 254).

In Fantásië herskep die vertaler Ende se nuwe verwysingsraamwerke vir die leser. Tydens Atreju en Bastian se reise word die leser slegs enkele kere daarvan bewus dat Die eindelose storie ' $\mathrm{n}$ vertaalde teks uit Duits is, onder andere bloot net omdat daar met 'drie mark en vyftien pennies' na die pre-Euro Duitse geldeenheid verwys word en omdat
Bastian in die pakkamer waar hy homself tuismaak om die boek te lees, aan die ander kinders in die klaskamer dink 'wat op hierdie einste oomblik Duits het' (bl.15). Deurgaans kan die leser met 'n geruste hart, ongehinderd deur talige faktore, Atreju en Bastian se avonture meemaak tot aan die emosionele en hoogs bevredigende einde van die boek - wat weer 'n nuwe begin beteken.

Die eindelose storie bied 'n nuwe leeservaring in Afrikaans, ongeag of ' $n$ mens die boek in 'n ander taal gelees of die film gesien het. Al bied Ende sy storie hoogs chronologies ('en toe', 'en toe') aan, is die boek vermaaklik en wek dit onophoudelik nuuskierigheid oor die volgende ongelooflike, verbeeldingryke taferele wat altyd binne-in 'n tipiese Endelogika funksioneer. Met Die eindelose storie skaar Michael Ende homself by J.R.R. Tolkien en J.K. Rowling se 'crossover literature' soos wat Sandra L. Beckett (2017:21) dit beskryf: 'Crossover literature acknowledges the continuum between children's and adults' understanding and experience. Knowledge, emotions, desires, and concerns are shared across generations'. Bastian en Atreju se vrese, teëspoed, ambisies, suksesse - al hul ervarings in die verbeeldingryke wêrelde vergesel deur unieke kreature - bied 'n ryk aanbod vir ouer en nuwe lesers. So sit die Afrikaanse weergawe inderdaad hierdie 'eindelose storie' voort.

\section{Literatuurverwysings}

Beckett, S.L., 2017, 'Crossover Literature', Oxford Research Encyclopedias, Literature March, 2-27. https://doi.org/10.1093/acrefore/9780190201098.013.176

Ende, M., 2018, Die eindelose storie, Protea Boekhuis, Pretoria. 